\title{
STAPHYLOCOCCUS AUREUS RESISTENTE À METICILINA EM UNIDADES DE TERAPIA INTENSIVA NO BRASIL
}

\section{ARTIGO DE REVISÃO}

JESUS, Patricia Vitorio De ${ }^{1}$, GONDIM, Stephanie Messias², PINHEIRO, Carla Santos Ribeiro ${ }^{3}$

JESUS, Patricia Vitorio De. GONDIM, Stephanie Messias. PINHEIRO, Carla Santos Ribeiro. Staphylococcus Aureus resistente à meticilina em Unidades de Terapia Intensiva no Brasil. Revista Científica Multidisciplinar Núcleo do Conhecimento. Ano 05, Ed. 11, Vol. 20, pp. 05-28. Novembro de 2020. ISSN: 2448-0959, Link de acesso: https://www.nucleodoconhecimento.com.br/saude/resistente-a-meticilina, DOI: 10.32749/nucleodoconhecimento.com.br/saude/resistente-a-meticilina

\section{RESUMO}

Introdução: As infecções relacionadas à assistência à saúde (IRAS) representam, atualmente, um dos desafios mais relevantes de saúde pública no Brasil e no mundo, em decorrência do aumento da resistência bacteriana. No ambiente hospitalar, principalmente nas Unidades de Terapia Intensiva (UTIs), a colonização por micro-organismos multirresistentes, tais como Staphylococcus aureus resistente à meticilina (MRSA), é tendencial, devido à baixa vulnerabilidade intrínseca dos pacientes enfermos desse setor e aos principais fatores de risco comumente expostos, como a utilização de dispositivos invasivos e a indiscriminada terapia antimicrobiana. Objetivo: Relatar a ocorrência de Staphylococcus aureus resistente à meticilina em pacientes das unidades de terapia intensiva no Brasil, assim como, avaliar seus fatores de risco relacionados aos pacientes internados nesses setores,

\footnotetext{
${ }^{1}$ Especialização em Análises Clínicas e Toxicológicas - Em andamento. Graduação em Bacharelado em Biomedicina.

${ }^{2}$ Especialização em Análises Clínicas e Toxicológicas - Em andamento. Graduação em Bacharelado em Biomedicina.

${ }^{3}$ Doutorado em Biotecnologia - PPGBIOTEC UEFS/FIOCRUZ. Graduação em Ciências Biológicas.

RC: 66829

Disponível em: https://www.nucleodoconhecimento.com.br/saude/resistente-ameticilina
} 
demonstrando a sua importância como patógeno nosocomial e reforçando o conhecimento acerca das medidas de monitoramento e controle para prevenção da disseminação dessas cepas no ambiente hospitalar. Metodologia: Este artigo é uma revisão bibliográfica de caráter narrativo, no qual os dados foram coletados nas bases de dados Literatura Latino-Americana e do Caribe em Ciências da Saúde (LILACS), Scientific Electronic Library Online (SCIELO), National Library of Medicine (PUBMED), Google Acadêmico e o SciVerse Science Direct (Elsevier), no período de janeiro a outubro de 2020, tendo sido selecionados artigos publicados entre os anos de 2009 e 2020, em português e inglês. Resultados: Foram selecionados ao todo 50 artigos. No Brasil os relatos das ocorrências MRSA se concentraram nas regiões Sul e Sudeste do país. Os fatores de risco comumente associados foram a realização de procedimentos invasivos, a gravidade das patologias de base, baixa adesão à higienização das mãos, bem como a uso indiscriminado de antimicrobianos. Como consequência do uso imoderado, a eficácia terapêutica desses fármacos tem reduzido, implicando no tempo e número de internação do paciente, e no aumento das taxas de morbidade e mortalidade de pacientes internados em UTIs. Com o propósito do controle desse agravo, estratégias administrativas e ações educativas, como higienização correta e frequente das mãos dos profissionais de saúde e colaboradores, implementação de vigilância epidemiológica e protocolos de cultura de vigilância ativa são fundamentais à segurança do paciente.

Palavras-chave: Staphylococcus aureus, Staphylococcus aureus resistente à meticilina, MRSA, Infecção hospitalar, Unidades de terapia intensiva.

\section{INTRODUÇÃO}

As Infecções Relacionadas à Assistência à Saúde (IRAS) representam um importante desafio de saúde pública em todo o mundo. São infecções adquiridas durante a prestação dos cuidados e procedimentos de saúde invasivos em hospitais e ambientes extra hospitalares, aos seus usuários, desde a atenção básica à alta complexidade e reabilitação, prolongando o tempo de internação, elevação dos

RC: 66829

Disponível em: https://www.nucleodoconhecimento.com.br/saude/resistente-ameticilina 
custos assistenciais e das taxas de mortalidade e morbidade, aumento da resistência microbiana e, consequentemente, redução da qualidade de vida do paciente (CRUZ; SILVA; MAGALHÃES, 2018).

As IRAS podem ser causadas tanto por micro-organismos presentes na própria microbiota endógena do paciente, quanto por fonte exógena. O contato do paciente com a microbiota do ambiente hospitalar, como os utensílios e equipamentos utilizados nos procedimentos de saúde, ou com os profissionais de saúde portadores ou contaminados, em especial através das mãos destes, podem servir como reservatórios de micro-organismos patogênicos afetando, principalmente, os indivíduos imunossuprimidos e imunodeprimidos (PEREIRA, B. et al., 2019). No Brasil, entre os pacientes internados em uma unidade de saúde, 15\% desenvolvem algum tipo de infeção relacionada à assistência à saúde (PEREIRA, et al., 2016), a qual é responsável por uma taxa de mortalidade que varia de 9 a 58\% (SOARES et al., 2017). Entre os micro-organismos mais comumente relacionados com as IRAS estão a Escherichia coli, Enterococcus sp, Klebsiella sp, Acinetobacter spp e Staphylococcus sp, sobretudo Staphylococcus aureus (BASTOS et al., 2020; MENEZES et al., 2018; PIMENTA, 2016).

O Staphylococcus aureus é uma bactéria oportunista residente da microbiota normal de cerca de $30 \%$ da população mundial, estando presente em diversos sítios anatômicos, em particular da pele e mucosas nasais (TONG et al., 2015). Entretanto, em condições nas quais ocorrem a ruptura da integridade da barreira cutânea, a exemplo dos traumas, procedimentos invasivos ou uma debilitação do sistema imunológico, o $S$. aureus passa a ser o causador habitual de infecções cutâneas, podendo se estender para o tecido subcutâneo e se alastrar pelo corpo, ocasionando doenças invasivas como bacteremias, abscessos, endocardites, pneumonia e osteomielites (DUARTE et al., 2018). Além disso, é o agente etiológico de maior prevalência associado às infecções adquiridas no ambiente hospitalar, sobretudo no setor de unidade de terapia intensiva (ALFOUZAN; DHAR; UDO, 2017).

RC: 66829

Disponível em: https://www.nucleodoconhecimento.com.br/saude/resistente-ameticilina 
Devido ao perfil de resistência antimicrobiana e sua elevada virulência, o $S$. aureus tornou-se um dos micro-organismos de maior importância médica quando se trata de infecções hospitalares e comunitárias (IFA, 2019). Essa capacidade de interferir no mecanismo de ação do antibiótico lhe confere, em mais de 50\% dos casos, o papel do principal patógeno no contexto das infecções relacionadas à assistência à saúde, com evolução para óbito em mais de 16\% dos pacientes (CAMILO; PEDER; SILVA, 2016).

Estima-se que todos os anos, em todo o mundo, cerca de 1,4 milhões de doentes são afetados por infecções relacionadas à assistência à saúde. Segundo relatórios publicados pela Organização Mundial da Saúde (OMS), a ocorrência desse agravo independe dos níveis de desenvolvimento socioeconômico e humano de um dado país, ou seja, mesmo que haja melhores políticas e práticas em relação aos processos de prestação de assistência à saúde tanto em países desenvolvidos, quanto em desenvolvimento, necessitam de orientações para melhor investir seus recursos nos cuidados à saúde (SOUSA et al., 2016). No Brasil, em detrimento da ausência de bancos de dados organizados de forma precisa e sistematizada, que traduzam em termos quantitativos a real prevalência de infecções nosocomiais em unidades de terapia intensiva, não há conhecimento relevante da avaliação dimensional desses micro-organismos no âmbito hospitalar e da importância desse agravo para a segurança do paciente (LIMA et al., 2015).

Frente aos altos índices de morbidade e mortalidade, e a elevada frequência de $S$. aureus multirresistentes associado às IRAS, o presente estudo tem por objetivo relatar a ocorrência de Staphylococcus aureus resistente à meticilina em pacientes das unidades de terapia intensiva no Brasil, assim como, avaliar seus fatores de risco relacionados aos pacientes internados nesses setores, demonstrando a sua importância como patógeno nosocomial e acrescentando conhecimento acerca das medidas de monitoramento e controle para prevenção da disseminação dessas cepas no ambiente hospitalar. 


\section{REVISÃO DE LITERATURA}

\subsection{UNIDADE DE TERAPIA INTENSIVA (UTI)}

As Unidades de Terapia Intensiva existentes nos hospitais são áreas críticas destinadas ao atendimento de pacientes graves ou de risco, instáveis hemodinamicamente, que necessitam de recursos tecnológicos necessários ao diagnóstico e atenção profissional especializada, da monitoração e vigilância contínua de suas condições vitais e de cuidados complexos que exigem assistência permanente. Por necessitarem de complexos procedimentos e intervenções terapêuticas, esses pacientes ficam mais vulneráveis a contrair uma infecção hospitalar quando submetidos aos cuidados em saúde, gerando condições favoráveis ao aparecimento de eventos adversos, que colocam em risco a segurança e a vida do paciente (CRUZ et al., 2018).

A probabilidade de desenvolvimento de uma infecção hospitalar e de sua gravidade nesse setor é de 5 a 10 vezes maior do que nos demais setores da unidade de saúde. Devido aos fatores de risco aos quais os pacientes internados em um setor de UTI estão expostos, cerca de 10 a 30\% desses indivíduos podem ser acometidos por algum tipo de infecção hospitalar, acarretando uma taxa de mortalidade entre 10 e 80\% (FRANÇA; FREITAS, 2019).

Esse setor é dividido em diferentes categorias, sendo estas: Adulto, destinada a pacientes com idade igual ou superior a 18 anos; Pediátrica, reservada a pacientes com idade de 29 dias a 14 ou 18 anos; Pediátrica Mista, destinada a pacientes recém-nascidos; Neonatal, designada a pacientes com idade entre 0 e 28 dias e as UTIs Especializadas, reservadas a pacientes selecionados por tipo de doença ou intervenção, dentre as quais destacam-se: Cardiológica, Cirúrgica e Neurológica. É constituída por uma equipe profissional de médicos, enfermeiros, fisioterapeutas, nutricionistas, psicólogos, entre outros (BRASIL, 2010).

RC: 66829

Disponível em: https://www.nucleodoconhecimento.com.br/saude/resistente-ameticilina 
Com o objetivo de estabelecer os requisitos mínimos necessários para o funcionamento das Unidades de Terapia Intensiva e a redução máxima dos riscos a todos os envolvidos no ambiente hospitalar, desde os pacientes aos profissionais de saúde, o Ministério da Saúde, por intermédio da Agência Nacional de Vigilância Sanitária (ANVISA), estabeleceu a resolução $\mathrm{n}^{0}$ 7, de 24 de fevereiro de 2010, onde as UTIs, sejam elas públicas ou privadas, civis ou militares, devem cumprir os requisitos mínimos dispostos no regulamento. A mesma visa esclarecer informações quanto à infraestrutura física de uma UTI, a privacidade, conforto e segurança dos pacientes (BRASIL, 2010).

A quantidade de leitos de UTI nos hospitais depende das características de porte e demanda que cada hospital necessita. Contudo no Brasil, os leitos destinados a esse tipo de área crítica não ultrapassam os $2 \%$, em contrapartida, apesar da pouca disponibilidade, ainda é o setor hospitalar com as maiores taxas de infeção (25\%) e mortalidade (CATÃO et al., 2013).

\subsection{RESISTÊNCIA ANTIMICROBIANA}

A descoberta da penicilina em 1928, por Alexander Fleming, foi um grande achado para a saúde pública. Apesar disso, as doenças infecciosas continuam a ser um grande problema para a humanidade, causando inúmeras mortes todos os anos, pois a partir dessa descoberta deu-se início a um grande problema: a resistência microbiana (SILVA; AQUINO, 2018).

O achado da resistência do $S$. aureus à penicilina, nos anos 60 , levou ao desenvolvimento do antimicrobiano beta-lactâmico meticilina, que, ao ligar-se às proteínas ligadoras de penicilina (PBPs - Penicillin-binding proteins), coíbem a síntese da parede celular, desencadeando, assim, a lise bacteriana. Entretanto, após um período foi-se verificado o desenvolvimento da resistência dessa bactéria pela meticilina, por meio da expressão do gene mecA, o qual codifica a PBP, alterando-a de modo a reduzir a sua afinidade às drogas beta-lactâmicas. Dessa forma, a biossíntese da parede celular não é afetada e a bactéria resiste à ação do

RC: 66829

Disponível em: https://www.nucleodoconhecimento.com.br/saude/resistente-ameticilina 
antibiótico beta-lactâmico, dando origem a cepas resistentes denominadas de Staphylococcus aureus meticilina resistente (MRSA - Methicillin Resistant S. aureus) (WATKINS; HOLUBAR; DAVID, 2019).

A resistência antimicrobiana é um processo natural pelo qual os micro-organismos sofrem ao responder à pressão seletiva realizada pelo uso de antibióticos, que, em consequência do seu uso indiscriminado, tem ocorrido com maior rapidez. Como resultado disso, pode-se citar a eficácia reduzida do tratamento e maior duração da infecção, aumento dos casos de hospitalização e repercussões clínicas e econômicas em razão do aumento das taxas de morbidade e mortalidade decorrente da demora em fornecer tratamentos eficazes contra infecções por cepas resistentes. Dentre os fatores relacionados ao uso indevido, têm-se a prescrição errônea do fármaco, principalmente por diagnóstico impreciso; a terapêutica incorreta; aumento da prescrição de antimicrobianos; o uso inadequado, tanto pelo não cumprimento do intervalo de tempo entre as doses, quanto pela interrupção do tratamento pelos pacientes; e a automedicação. Com isso a Organização Mundial da Saúde (OMS) juntamente com outras organizações relacionadas à saúde, reconhece que a problemática da resistência antimicrobiana é uma ameaça crescente para a saúde pública mundialmente e admitem a importância de desenvolver sistemas de vigilância e controle dessa questão (LOUREIRO et al., 2016).

As cepas de MRSA, inicialmente associadas estritamente ao ambiente hospitalar, passaram a ser detectadas na comunidade, em indivíduos saudáveis, em casos de infecções de pele e subcutânea como foliculites, erisipelas e furúnculo, sem alguma relação com o meio hospitalar. Para defini-las como MRSA adquirida na comunidade (CA-MRSA), é necessário que os indivíduos acometidos não tenham fatores de risco para MRSA nosocomial - procedimentos cirúrgicos invasivos, internamento prévio ou uso de cateter venoso por tempo prolongado - ou terem sido admitidos no hospital em um período de tempo inferior a 48 horas, evitando assim o falso diagnóstico de infecção por MRSA hospitalar (HA-MRSA) e de identificação laboratorial (GURUNG; MAHARJAN; CHHETRI, 2020; SIQUEIRA et al., 2018). Outra diferença entre a CA-MRSA e a HA-MRSA está relacionada com a RC: 66829

Disponível em: https://www.nucleodoconhecimento.com.br/saude/resistente-ameticilina 
antimicrobianoterapia, pois a cepa MRSA associada à comunidade apresenta resistência somente à meticilina e demais beta-lactâmicos, enquanto a MRSA hospitalar pode se apresentar resistente a outras drogas, a citar: clindamicina, eritromicina, tetraciclina e gentamicina (FREITAS et al., 2016).

Grande parte dos antimicrobianos são sintetizados de forma natural e essa característica beneficia o desenvolvimento de mecanismos de resistência pelos micro-organismos por meio da ocorrência de mutações; síntese de enzimas para inibir ou suprimir a ação da droga; aquisição de material genético mais resistentes, através de transferências ou da intermediação dos plasmídeos e transposons; bombas de efluxo; alteração na conformação do sítio de ação, reduzindo ou impedindo a sua afinidade pelo composto farmacológico; e a redução da absorção de moléculas exógenas (SILVA; AQUINO, 2018).

Como consequência à evolução e aumento da resistência microbiana, faz-se imprescindível a pesquisa e desenvolvimento de novas drogas mais eficazes para combater os micro-organismos resistentes. Pharmaceutical Research and Manufacturers of America (PhRMA) (2018) apresentou uma lista de novos compostos farmacológicos, os quais se encontram em fase de testes, de aprovação e outros já aprovados pelo Food and Drug Administration (FDA), desenvolvidos com o intuito de tratar as infecções causadas por micro-organismos patogênicos, muitos dos quais já se encontram resistentes aos antimicrobianos disponíveis no mercado. Como exemplos desses fármacos, pode-se citar o reltecimod (AB-103); gepotidacin; BC-7013; e dentre aqueles elaborados para o tratamento de cepas MRSA, a dalbavancina, lefamulin, iclaprim, fosfomycin, omadacycline e afabicin.

\subsection{DIAGNÓSTICO LABORATORIAL - DETECÇÃO E IDENTIFICAÇÃO PARA STAPHYLOCOCCUS AUREUS RESISTENTE À METICILINA}

Dentre vários micro-organismos envolvidos nos processos de infecção hospitalar, o Staphylococcus aureus é um dos principais e mais importantes devido à sua alta

RC: 66829

Disponível em: https://www.nucleodoconhecimento.com.br/saude/resistente-ameticilina 
capacidade de desenvolver resistência antibiótica, sendo responsável pelo desenvolvimento de bacteremias, infecções relacionadas a procedimentos cirúrgicos e das vias aéreas inferiores (GARCIA; SILVA; OLIVEIRA, 2019). O S. aureus é uma bactéria pertencente à família Micrococcaceae e ao gênero Staphylococcus, com morfologia em forma de cocos, lisa, brilhante, de coloração amarelo-ouro; é uma bactéria gram positiva, não esporulada, com presença de cápsula, facultativa, imóvel e com elevada capacidade de colonização e de sobrevivência quando em contato com o meio ambiente e superfícies (AMADOR; BASSO; VIEIRA, 2018; SILVA, 2017).

A identificação das infecções localizadas por $S$. aureus, geralmente, é feita apenas com base no diagnóstico clínico, não sendo necessário realizar identificação laboratorial. O que, para os casos de infeções sistêmicas, não é suficiente. Para esses casos, é imprescindível a identificação laboratorial incluindo a linhagem de $S$. aureus e o teste de suscetibilidade microbiana para implementar o tratamento mais apropriado (ZURITA; GUZMÁN-BLANCO, 2010).

Os testes, usualmente utilizados na microbiologia clínica para identificação de isolados de $S$. aureus, baseiam-se em distingui-los de outras espécies estafilocócicas. O método a ser utilizado para esse procedimento dependerá das circunstâncias envolvidas em cada caso, sendo a microscopia direta combinado a técnica de coloração de Gram, o método inicial e mais rápido de identificação na qual é possível distinguir as bactérias em Gram-positivas e em Gram-negativas (BRASIL, 2013; ZURITA; MEJIA; BLANCO, 2010).

$\mathrm{Na}$ rotina laboratorial, as provas utilizadas para identificação ou confirmação de $S$. aureus, segundo orientações da BSAC/HIS/ICNA, são os testes da catalase, sendo o diagnóstico presuntivo para distinguir estafilococos dos estreptococos; de coagulase, que verifica a presença da proteína enzimática coagulase livre; e o teste da DNase, baseado na reação degradativa da enzima desoxirribonuclease, produzida por alguns micro-organismos, sobre o DNA (BRASIL, 2013). Como complemento para essa identificação, são realizados os testes de fermentação de

RC: 66829

Disponível em: https://www.nucleodoconhecimento.com.br/saude/resistente-ameticilina 
manitol, o qual verifica a capacidade da bactéria em fermentar o manitol do meio de cultura; o de resistência à novobiocina, usado como parâmetro de confirmação que a amostra é de fato coagulase positiva; e o antibiograma, com finalidade de determinar a sensibilidade do micro-organismo, in vitro, aos antimicrobianos (HOLANDA; ARIMATEIA; MOTTA NETO, 2017).

O diagnóstico de Staphylococcus aureus meticilina resistente (MRSA) é realizado por meio da associação dos sintomas clínicos apresentados, dados epidemiológicos e na determinação da linhagem infecciosa de MRSA. Há normas publicadas em vários países detalhando os protocolos e os procedimentos a serem seguidos para realizar a identificação de uma cepa MRSA. Alguns desses documentos normativos são o Clinical and Laboratory Standards Institute (CLSI) (Instituto de Padrões Clínicos e Laboratoriais), nos Estados Unidos; O Sistema Europeu de Vigilância da Resistência Antimicrobiana (EARSS); Sociedade Espanhola de Infectologia e Microbiologia Clínica (SEIMC); British Society for Antimicrobial Chemotherapy (BSAC); e Organização Pan-Americana de Saúde (OPAS), na América Latina. Entretanto, essas normas diferem no detalhamento de suas informações, não sendo uma recomendação padrão internacional, logo, é necessário que seja selecionada uma normativa a ser seguida e adaptá-la às necessidades local (ZURITA; GUZMÁN-BLANCO, 2010).

No Brasil, o Ministério da Saúde e Secretaria de Vigilância em Saúde, no dia 11 de dezembro de 2018, publicaram no Diário Oficial da União, a Portaria ํㅡ 64, a qual determina que todos os laboratórios clínicos, tanto os públicos quanto os privados, do território brasileiro, passem a utilizar o BrCast (Brazilian Committee on Antimicrobial Susceptibility Testing), versão brasileira do European Committee on Antimicrobial Susceptibility Testing (EUCAST), como as normas de interpretação para os testes de sensibilidade aos antimicrobianos (TSA) (BRASIL, 2018). Essa modificação nas normas de interpretação aos TSA ocorreu devido ao EUCAST apresentar critérios revisados e atualizados mais recentemente do que o CLSI, que continua a utilizar muitos critérios antigos para esses testes (LABNETWORK, 2016).

RC: 66829

Disponível em: https://www.nucleodoconhecimento.com.br/saude/resistente-ameticilina 


\section{METODOLOGIA}

Para o alcance dos objetivos deste estudo, optou-se pelo método do tipo revisão bibliográfica, de caráter narrativo a respeito das ocorrências de infecções nosocomiais por Staphylococcus aureus resistente à meticilina em pacientes das unidades de terapia intensiva no Brasil.

O levantamento dos artigos foi realizado entre os meses de janeiro a outubro de 2020, nas bases de dados Literatura Latino-Americana e do Caribe em Ciências da Saúde (LILACS), Scientific Electronic Library Online (SCIELO), National Library of Medicine (PUBMED), Google Acadêmico e o SciVerse Science Direct (Elsevier), utilizando-se a combinação de descritores controlados, cadastrados nos Descritores em Ciências da Saúde (DeCS): Staphylococcus aureus; Staphylococcus aureus resistente à meticilina; MRSA; Infecção hospitalar; Unidades de terapia intensiva.

Foram definidos como critérios de inclusão: artigos publicados entre os anos de 2009 e 2020, em português e inglês, cujos assuntos abordassem a lógica da pertinência temática assim como da relevância das atribuições teóricas por eles trazidos. Os critérios de exclusão: periódicos publicados anteriormente ao ano de 2009 e que tivessem como foco principal MRSA adquirido na comunidade; artigos que se referiam a ocorrência de infecções nosocomiais por decorrência de outros micro-organismos e em outros setores hospitalares e que se repetissem nas bases de dados.

\section{RESULTADOS E DISCUSSÃO}

A partir da definição do tema a ser abordado neste artigo, dos descritores controlados oriundos do cadastro dos Descritores em Ciências da Saúde e com base nos critérios de inclusão e exclusão, obteve-se 144 estudos publicados nas bases de dados mencionados anteriormente, dos quais 50 foram selecionados para a produção desse artigo. Salienta-se que os demais artigos, 94, por não estarem no 
período proposto para esta pesquisa ou não focassem no tema deste trabalho, foram excluídos.

Após a leitura dos 50 artigos que atenderam aos critérios de inclusão, foram escolhidos 16 estudos com pesquisa experimental, afim de analisar e sintetizar os pontos centrais por eles abordados. Pode-se observar no Quadro 1, que a seleção dos artigos explorados se deu através do nome do (s) autor (es) e quanto ao ano de publicação, título, objetivos e pela descrição dos principais resultados.

Quadro 1 - Caracterização dos principais estudos experimentais, segundo os autores e ano de publicação, título, objetivos e principais resultados.

\begin{tabular}{|c|c|c|c|}
\hline Autores & Título do artigo & Objetivos & $\begin{array}{l}\text { Principais } \\
\text { resultados }\end{array}$ \\
\hline $\begin{array}{l}\text { BULLÉ, } \\
\text { Danielly Joani } \\
\text { et al. (2016) }\end{array}$ & $\begin{array}{l}\text { Prevalência de } \\
\text { Staphylococcus } \\
\text { aureus meticilina } \\
\text { resistentes em } \\
\text { profissionais de } \\
\text { saúde. }\end{array}$ & $\begin{array}{l}\text { Determinar a } \\
\text { prevalência de } \\
\text { portadores } \\
\text { assintomáticos de } \\
\text { Staphylococcus } \\
\text { aureus resistente à } \\
\text { meticilina (MRSA) } \\
\text { presente na mucosa } \\
\text { nasal de } \\
\text { profissionais de } \\
\text { saúde. }\end{array}$ & $\begin{array}{l}\text { Detectou-se uma } \\
\text { prevalência de } \\
\text { Staphylococcus } \\
\text { aureus resistente à } \\
\text { meticilina de } 26,9 \% \text {. }\end{array}$ \\
\hline $\begin{array}{l}\text { CAMILO, Carla } \\
\text { Juliana; } \\
\text { PEDER, Leidy } \\
\text { Daiane de; } \\
\text { SILVA, } \\
\text { Claudinei }\end{array}$ & $\begin{array}{l}\text { Prevalência de } \\
\text { Staphylococcus } \\
\text { aureus meticilina } \\
\text { resistente em } \\
\text { profissionais de } \\
\text { enfermagem. }\end{array}$ & $\begin{array}{l}\text { Avaliar a prevalência } \\
\text { de } S \text {. aureus nas } \\
\text { mãos e mucosa } \\
\text { nasal de } \\
\text { profissionais de } \\
\text { enfermagem de um }\end{array}$ & $\begin{array}{l}\text { Verificou-se uma } \\
\text { taxa de } 8 \% \text { de } \\
\text { Staphylococcus } \\
\text { aureus meticilina } \\
\text { resistente entre os } \\
\text { profissionais de }\end{array}$ \\
\hline
\end{tabular}

RC: 66829

Disponível em: https://www.nucleodoconhecimento.com.br/saude/resistente-ameticilina 


\begin{tabular}{|c|c|c|c|}
\hline $\begin{array}{l}\text { Mesquita da. } \\
(2016)\end{array}$ & & $\begin{array}{l}\text { hospital de Cascavel } \\
\text { (PR). }\end{array}$ & enfermagem. \\
\hline $\begin{array}{l}\text { CASTRO- } \\
\text { OROZCO, } \\
\text { Raimundo et } \\
\text { al. (2019) }\end{array}$ & $\begin{array}{l}\text { Antimicrobial } \\
\text { resistance trends in } \\
\text { methicillin-resistant } \\
\text { and methicillin- } \\
\text { susceptible } \\
\text { Staphylococcus } \\
\text { aureus and } \\
\text { Staphylococcus } \\
\text { epidermidis isolates } \\
\text { obtained from } \\
\text { patients admitted to } \\
\text { intensive care units. } \\
2010-2015 \text {. }\end{array}$ &  & $\begin{array}{l}\text { Identificou-se } \\
63,6 \% \text { de cepas } \\
\text { meticilina } \\
\text { resistente, das } \\
\text { quais } 13,7 \% \text { foram } \\
\text { Staphylococcus } \\
\text { aureus resistente à } \\
\text { meticilina. }\end{array}$ \\
\hline $\begin{array}{l}\text { CATÃO, Raissa } \\
\text { Mayer Ramalho } \\
\text { et al. (2013) }\end{array}$ & $\begin{array}{l}\text { Prevalência de } \\
\text { infecções } \\
\text { hospitalares por } \\
\text { Staphylococcus } \\
\text { aureus e perfil de } \\
\text { suscetibilidade aos } \\
\text { antimicrobianos. }\end{array}$ & \begin{tabular}{lr} 
Analisar & a \\
prevalência & das \\
infecções & \\
hospitalares & \\
causadas & por \\
Staphylococcus & \\
aureus e & sua \\
resistência & aos \\
\multicolumn{2}{l}{ antimicrobianos. }
\end{tabular} & 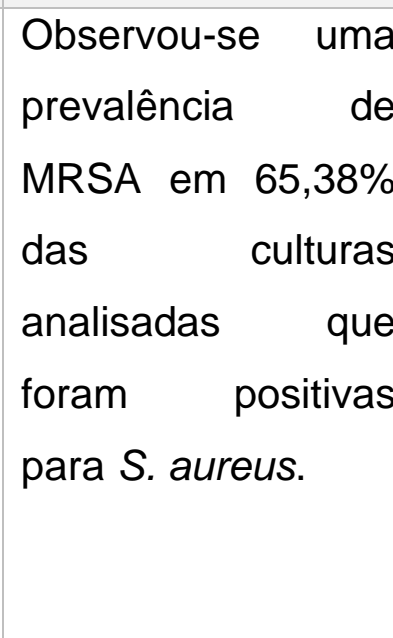 \\
\hline RUVINEL, & Perfil & Identificar 0 perfil & Encontrou-se uma \\
\hline
\end{tabular}

RC: 66829

Disponível em: https://www.nucleodoconhecimento.com.br/saude/resistente-ameticilina 
R.; SILVEIRA, antimicrobiano de antimicrobiano de frequência de 95\%

A. R.; SOARES, Staphylococcus

J. S. (2011)

CRUZ, Renata Perfil

Fiuza; SILVA, microbiológico dos

Gabriela

Matheus

Messias;

MAGALHÃES,

Maria

da hospital

Consolação. universitário da

(2018)

UTI no Distrito

submetidos

ativa em um
Região Sudeste de Minas Gerais.
Staphylococcus

aureus isolados de

pacientes adultos

hospitalizados em antimicrobiano,

unidade de terapia sendo 35\% MRSA.

intensiva do Hospital

Regional de

Ceilândia, no Distrito

Federal.

Identificar o perfil A prevalência de

microbiológico dos MRSA foi de $46,9 \%$

pacientes

à submetidos à cultura

de vigilância ativa.

GARCIA,

Patricia

Guedes;

SILVA, Isabela

Aparecida

Ribeiro

da;

OLIVEIRA,

Leonardo

de Staphylococcus

aureus resistente a algum

e $61,5 \%, \quad$ em

pacientes

transferidos de

outra instituição

com permanência

maior que 96 horas

ou

internação

mínima de 48

horas,

respectivamente.

Colonização por Identificar

prevalência

a Identificou-se

a

Staphylococcus

de

aureus resistente à

MRSA em culturas

prevalência

de

meticilina

em de

vigilância

pacientes

de epidemiológica

das culturas de

vigilância

através de swab epidemiológica.

nasal de pacientes

internados nas UTIs

RC: 66829

Disponível em: https://www.nucleodoconhecimento.com.br/saude/resistente-a- 
Romaniello

Gama

de.

(2019)

GONÇALVES, Incidência de

Ana Cristina infecções

Nunes et

al. provocadas

(2013)

Staphylococcus aureus resistente a meticilina em um hospital da zona sul do Rio de Janeiro.

\begin{tabular}{|c|c|c|c|}
\hline & & 2013. & \\
\hline $\begin{array}{l}\text { MORAES, } \\
\text { Graciana Maria } \\
\text { de et al. (2013) }\end{array}$ & $\begin{array}{l}\text { Infecção ou } \\
\text { colonização por } \\
\text { micro-organismos } \\
\text { resistentes: } \\
\text { identificação de } \\
\text { preditores. }\end{array}$ & $\begin{array}{l}\text { Identificar os fatores } \\
\text { preditores de } \\
\text { infecção ou } \\
\text { colonização por } \\
\text { micro-organismos } \\
\text { resistentes. }\end{array}$ & $\begin{array}{lr}\text { Verificou-se que } & \text { na } \\
\text { população } & \text { do } \\
\text { estudo } & \text { a } \\
\text { prevalência } & \text { de } \\
\text { MRSA foi } & \text { de } \\
54,5 \% & \end{array}$ \\
\hline $\begin{array}{l}\text { MOREIRA, Ana } \\
\text { Cândida } \\
\text { Martins Grossi; } \\
\text { SANTOS, } \\
\text { Rosiane } \\
\text { Ribeiro dos; } \\
\text { BEDENDO, } \\
\text { João. (2013) }\end{array}$ & $\begin{array}{l}\text { Prevalência e perfil } \\
\text { de sensibilidade de } \\
\text { Staphylococcus } \\
\text { aureus isolados em } \\
\text { pacientes e equipe } \\
\text { de enfermagem. }\end{array}$ & $\begin{array}{l}\text { Determinar a } \\
\text { prevalência e o perfil } \\
\text { de susceptibilidade } \\
\text { de amostras de } \\
\text { Staphylococcus } \\
\text { aureus isoladas em } \\
\text { pacientes } \\
\text { membros da equipe } \\
\text { de enfermagem de } \\
\text { uma UTI de um } \\
\text { hospital geral. }\end{array}$ & $\begin{array}{l}\text { A prevalência de } \\
\text { MRSA entre os } \\
\text { pacientes foi de } \\
63,93 \% \text { e } 68,85 \% \text {, } \\
\text { pelo teste da CIM e } \\
\text { pelo método de } \\
\text { disco difusão, } \\
\text { respectivamente. }\end{array}$ \\
\hline NASCIMENTO, & Methicillin-resistant & Caracterizar & O Staphyolococcus \\
\hline
\end{tabular}

de um hospital de Minas Gerais.

\begin{tabular}{|lr|lr} 
Avaliar a & incidência & 132 & amostras \\
de infecções & positivas & para \\
provocadas por & Staphylococcus
\end{tabular}
MRSA em um aureus, sendo que hospital da zona sul $44 \quad$ foram do Rio de Janeiro, resistentes à no período de março meticilina. de 2012 a março de 2013.

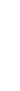




\begin{tabular}{|c|c|c|c|}
\hline $\begin{array}{l}\text { hiago C. et al. } \\
\text { 018) }\end{array}$ & $\begin{array}{l}\text { Staphylococcus } \\
\text { aureus isolated } \\
\text { from na intensive } \\
\text { care unit in Minas } \\
\text { Gerais, Brazil, over } \\
\text { a six-year period. }\end{array}$ & $\begin{array}{l}\text { isolados de } \\
\text { Staphylococcus } \\
\text { aureus resistente à } \\
\text { meticilina em uma } \\
\text { unidade de terapia } \\
\text { intensiva de um } \\
\text { hospital universitário } \\
\text { de atendimento } \\
\text { terciário, entre } 2005 \\
\text { e } 2010 \text {. }\end{array}$ & $\begin{array}{lr}\begin{array}{lr}\text { aureus } \\
\text { prevalente }\end{array} & \text { foi } \\
59,2 \% & \text { dos } \\
\text { pacientes } & \\
\text { internados na } & \text { UTI. }\end{array}$ \\
\hline $\begin{array}{l}\text { OGUEIRA, } \\
\text { aula Sacha } \\
\text { cota et al. } \\
009)\end{array}$ & $\begin{array}{l}\text { Perfil da infecção } \\
\text { hospitalar em um } \\
\text { hospital } \\
\text { universitário. }\end{array}$ & $\begin{array}{l}\text { Verificar taxa de } \\
\text { prevalência de } \\
\text { infecção hospitalar, } \\
\text { tipos de infecções, } \\
\text { patógenos e seu } \\
\text { perfil de } \\
\text { sensibilidade aos } \\
\text { antimicrobianos. }\end{array}$ & $\begin{array}{l}\text { O Staphylococos } \\
\text { aureus foi o micro- } \\
\text { organismo } \\
\text { responsável por } \\
20 \% \text { das IH, com } \\
\text { elevado perfil de } \\
\text { sensibilidade à } \\
\text { meticilina }(77,3 \%) \text {. }\end{array}$ \\
\hline $\begin{array}{l}\text { LIVEIRA, } \\
\text { aniele Martins } \\
\text { e Sousa et al. } \\
\text { 2018) }\end{array}$ & $\begin{array}{l}\text { High rates of } \\
\text { methicillin-resistant } \\
\text { Staphylococcus } \\
\text { aureus colonisation } \\
\text { in a Brazilian } \\
\text { Intensive Care Unit. }\end{array}$ & $\begin{array}{l}\text { Avaliar a taxa de } \\
\text { colonização de } \\
\text { Staphylococcus } \\
\text { aureus na orofaringe } \\
\text { e do local de } \\
\text { inserção } \\
\text { cateteres venoso } \\
\text { central em pacientes } \\
\text { de unidade de } \\
\text { terapia intensiva. }\end{array}$ & $\begin{array}{lr}\text { Encontrou-se } & \text { uma } \\
\text { taxa colonização } & \\
\text { por MRSA } & \text { em } \\
26,4 \% & \text { dos } \\
\text { participantes } & \text { do } \\
\text { estudo. } & \end{array}$ \\
\hline 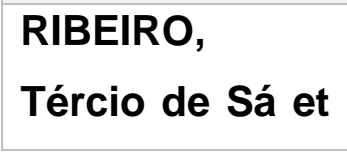 & $\begin{array}{l}\text { Ocorrência e perfil } \\
\text { bacteriano de }\end{array}$ & $\begin{array}{lr}\text { Verificar } & a \\
\text { ocorrência e o perfil }\end{array}$ & $\begin{array}{l}\text { Observou-se uma } \\
\text { ocorrência de } S \text {. }\end{array}$ \\
\hline
\end{tabular}




\begin{tabular}{|c|c|c|c|}
\hline al. (2019 & $\begin{array}{l}\text { culturas coletadas } \\
\text { em pacientes } \\
\text { internados na } \\
\text { unidade de terapia } \\
\text { intensiva em um } \\
\text { hospital terciário. }\end{array}$ & $\begin{array}{l}\text { bacteriano presente } \\
\text { em pacientes } \\
\text { internados na UTI de } \\
\text { um hospital } \\
\text { universitário. }\end{array}$ & $\begin{array}{l}\text { aureus em } 14 \% \text { das } \\
\text { secreções traqueais } \\
\text { e de } 12,8 \% \text { nas } \\
\text { hemoculturas. }\end{array}$ \\
\hline \begin{tabular}{l}
\multicolumn{2}{l}{ RODRIGUES, } \\
Mônica de \\
Abreu et al. \\
$(2015)$
\end{tabular} & $\begin{array}{l}\text { Prevalence of } \\
\text { methicillin-resistant } \\
\text { Staphylococcus } \\
\text { aureus in a } \\
\text { University Hospital } \\
\text { in the South of } \\
\text { Brazil. }\end{array}$ & $\begin{array}{l}\text { Analisar a } \\
\text { predominância de } \\
\text { MRSA em um } \\
\text { hospital universitário } \\
\text { do sul do Brasil, } \\
\text { entre } 2007 \text { e } 2011 .\end{array}$ & $\begin{array}{lr}\text { Constatou-se } & \text { que } \\
\text { das } & 33,3 \% \\
\text { amostras } & \text { positivas } \\
\text { para } & \text { MRSA, } \\
15,13 \% & \text { foram } \\
\text { provenientes } & \text { da } \\
\text { UTI. }\end{array}$ \\
\hline $\begin{array}{l}\text { SIQUEIRA, } \\
\text { Carla. C. M. et } \\
\text { al. (2018) }\end{array}$ & $\begin{array}{l}\text { Prevalence and } \\
\text { antimicrobial } \\
\text { susceptibility profile } \\
\text { of microorganisms } \\
\text { in a university } \\
\text { hospital from } \\
\text { Vitória, ES, Brazil. }\end{array}$ & $\begin{array}{l}\text { Avaliar a prevalência } \\
\text { e o perfil de } \\
\text { suscetibilidade } \\
\text { antimicrobiana das } \\
\text { Infecções } \\
\text { Relacionadas à } \\
\text { Assistência à Saúde } \\
\text { em um hospital } \\
\text { filantrópico } \\
\text { referência de } \\
\text { Espírito } \\
\text { Brasil. }\end{array}$ & $\begin{array}{l}\text { Detectou-se a } \\
\text { presença de MRSA } \\
\text { em 27,8\% e 41,4\%, } \\
\text { das amostras de } \\
\text { sangue } \\
\text { secreções, } \\
\text { respectivamente. }\end{array}$ \\
\hline
\end{tabular}

Legenda: MRSA - Staphylococcus aureus resistente à meticilina; S. aureus Staphylococcus aureus; CIM - concentração inibitória mínima; UTI - unidade de terapia intensiva; IH - Infecção hospitalar.

Fonte: Os autores, 2020.

RC: 66829

Disponível em: https://www.nucleodoconhecimento.com.br/saude/resistente-ameticilina 
O processo de desenvolvimento da resistência bacteriana aos antimicrobianos é um fenômeno natural que ocorre em consequência da pressão seletiva exercida por esses fármacos. Entretanto, quando o consumo dessas drogas é realizado de forma inadequada e indiscriminada, esse processo é acelerado, gerando um desenvolvimento crescente e desenfreado da resistência em bactérias que, anteriormente, eram suscetíveis aos antibióticos usualmente utilizados na prática clínica, resultando em diminuição da eficácia terapêutica, na hospitalização prolongada, no crescimento do número de hospitalizações e aumento das taxas de morbilidade e mortalidade. Com isso, o aumento da resistência antimicrobiana é, atualmente, considerado um dos maiores problemas de saúde pública a nível mundial (LOUREIRO et al., 2016; RIBEIRO et al., 2019).

Nesse contexto, Michelin e Fonseca (2018) ressaltam a problemática das infecções relacionadas à assistência à saúde em unidades de terapia intensiva, pois devido à condição clínica demasiadamente sensível, à realização de procedimentos invasivos ao longo do tempo de internação, a gravidade das patologias de base, bem como a administração intensa de antimicrobianos e a baixa adesão à higienização das mãos, tornam os pacientes internados nesse setor hospitalar os sujeitos mais propensos à aquisição de infecções e ao óbito por este agravo.

Entre os anos de 2010 e 2014, estudos internacionais a respeito da prevalência de MRSA em diferentes continentes indicaram uma proporção de quase $30 \%$ na África e uma média de $55 \%$ na América do Norte e na América Latina. No Brasil, tem sido relatado frequências de $34,1 \%$ a $46 \%$. No ano de 2015, o Sistema Europeu de Vigilância de Resistência Antimicrobiana (ECDC) fez uma pesquisa de $S$. aureus a partir de amostras de sangue coletadas de indivíduos de diferentes nacionalidades, onde pôde-se constatar a Romênia como país europeu de maior prevalência $(57,2 \%)$ e a Islândia como país de menor prevalência (0\%) (DUARTE et al., 2018).

Alguns estudos sobre $S$. aureus isolados de amostras provenientes de pacientes das unidades de terapia intensiva no Brasil, afirmam que $70 \%$ desses micro-organismos são do tipo MRSA, enquanto em outros estudos esse índice chega a atingir até $80 \%$.

RC: 66829

Disponível em: https://www.nucleodoconhecimento.com.br/saude/resistente-ameticilina 
Esses altos índices de MRSA presentes em unidades de terapia intensiva é um indicativo de que uma difusão da resistência antimicrobiana está ocorrendo no ambiente nosocomial, principalmente nas unidades de terapia intensiva (LIMA et al., 2015; NASCIMENTO et al., 2018; SOUSA et al., 2016; TEIXEIRA et al., 2016). Nesse ambiente, a baixa vulnerabilidade intrínseca dos pacientes criticamente enfermos corresponde a $20 \%$ do total de infecções de um hospital em comparação com as demais unidades. Os principais fatores de risco a que estão expostos esses pacientes incluem geralmente idade superior a 60 anos, as suas condições nutricionais associados ao tempo de permanência em unidades de terapia intensiva e a gravidade da enfermidade, bem como a realização rotineira de procedimentos invasivos como o cateter venoso central (CVC) e ventilação mecânica (VM), ou ainda, a indiscriminada terapia antimicrobiana de amplo espectro e a baixa adesão à higienização das mãos, que favorecem a ampla proliferação de micro-organismos (5 a 10 vezes), especialmente cepas multirresistentes de relevância epidemiológica (SOUSA et al., 2016).

No contexto nacional, enquanto Castro-Orozco et al. (2019) relatam que o risco de contaminação do paciente por uma $\mathrm{IH}$ é cerca de $10 \%$, podendo chegar a $40 \%$ quando se trata de internamento em unidades de terapia intensiva, Ferreira et al. (2019) afirmam que $20 \%$ de todas as infecções diagnosticadas no âmbito hospitalar provém dos pacientes hospitalizados na UTI. Porém todos concordam que o número de casos de MRSA nas UTIs pode indicar a necessidade de modificação e atualização das técnicas empregadas pela unidade de saúde para controlar e reduzir a resistência antimicrobiana, tais como: rigorosos cuidados com a higiene e desinfecção do ambiente hospitalar como um todo; higienização correta e frequente das mãos dos profissionais de saúde e colaboradores, reduzindo assim a colonização e, consequentemente, a infecção cruzada; a implementação de estudos de vigilância epidemiológica, pois essas medidas, quando postas em prática, possuem uma eficácia de até $70 \%$ na redução das IRAS e, portanto, da disseminação de cepas resistentes de $S$. aureus. 
Em uma pesquisa realizada por Catão et al (2013) em um hospital da Paraíba, foi constatado que o setor hospitalar com maior prevalência de infecções hospitalares por MRSA foi a UTI (88,24\%). Nesse estudo, 1056 prontuários e fichas técnicas foram analisados, dos quais $358(33,90 \%)$ relatavam crescimento bacteriano positivo, sendo 175 (48,88\%) casos de infecção hospitalar. Desses 175 casos, 26 $(14,86 \%)$ tiveram como agente etiológico o S. aureus, sendo 17 deles $(65,38 \%)$ positivos para Staphylococcus aureus resistentes à meticilina.

Ratificando a ideia de Castro-Orozco et al. (2019) e de Ferreira et al. (2019), Ribeiro et al. (2019) ressaltam a importância de conhecer a microbiota do ambiente hospitalar, pois essa prática constante resulta em uma vigilância mais assertiva do perfil de resistência dos micro-organismos desse ambiente, resultando em um melhor direcionamento terapêutico aos pacientes acometidos, além de auxiliar na vigilância das IRAS.

As principais formas de transmissão das cepas multirresistentes de MRSA no ambiente hospitalar advém de forma permanente ou transitória. $\mathrm{Na}$ forma permanente, tanto profissionais de saúde, quanto o espaço físico, atuam como vetores direta ou indiretamente nas infecções cruzadas, ou seja, a disseminação ocorre pelo contato direto dos profissionais de saúde portadores de $S$. aureus na cavidade nasal com os pacientes, fômites ou superfícies. Ademais, a forma transitória decorre do contato paciente para com paciente (LOPES et al., 2018). A disseminação desses patógenos no ambiente hospitalar está associada a ineficientes ou negligenciados procedimentos de higienização das mãos e de cuidados precários por parte dos profissionais de saúde nas aplicações dos dispositivos invasivos nos pacientes (BULLÉ et al., 2016). Entretanto, ainda que haja uma melhor adesão às práticas para prevenção no ambiente hospitalar e com a quantidade de medicamentos existentes no mercado, a contaminação cruzada não deixa de acontecer, os micro-organismos, em especial as bactérias, como a Staphylococcus aureus, continuam sendo os principais agentes responsáveis pela colonização e infecção dos seres humanos (BRASIL, 2013). 
A aproximação física das mãos dos profissionais de saúde no momento da assistência aos pacientes é inevitável. Bullé et al. (2016), ao realizarem um estudo em um hospital-escola no interior do Rio Grande do Sul, com amostras de swab da mucosa nasal de 29 profissionais de saúde que trabalhavam em alguns setores hospitalar, dentre eles a UTI, no período de março a abril de 2012, verificaram que dos $89,7 \%$ (26) dos profissionais participantes da pesquisa, tiveram amostras positivas para Staphylococcus aureus, sendo 7 delas MRSA. Igualmente, Camilo, Peder e Silva (2016), ao estudarem amostras das mãos e da mucosa nasal de 50 profissionais de enfermagem de um hospital da cidade de Cascavel, Paraná, durante o período de agosto a outubro de 2015 , evidenciaram $56 \%$ de presença de $S$. aureus, com $8 \%$ MRSA, sendo que $50 \%$ dos colaboradores atuavam na unidade de terapia intensiva do referido hospital.

Conforme Moreira, Santos e Bedendo (2013), ao determinarem a prevalência de Staphylococcus aureus nas mãos e secreções nasais em pacientes da UTI de um hospital da região norte do Paraná, entre março e junho de 2010, encontraram uma taxa de ocorrência de carreamento de $S$. aureus em aproximadamente $54,76 \%$ dos pacientes, dos quais $63,93 \%$, apresentaram resistência à meticilina pelo teste da CIM (concentração inibitória mínima) e 68,85\% pelo método de disco difusão.

Tanto para Amador, Basso e Vieira (2018) como para Renner e Carvalho (2013), S. aureus e Staphylococcus aureus resistente à meticilina são as espécies estafilocócicas mais importantes associadas às IRAS e as de maiores riscos para os pacientes debilitados da UTI. Nascimento et al. (2018), estudando isolados de MRSA obtidos de pacientes internados na UTI de um hospital universitário em Minas Gerais, entre 2005 e 2010, observaram que a prevalência de $S$. aureus meticilina resistente foi de $59,2 \%$. Nesse estudo, os isolados de MRSA apresentaram taxas de resistência superiores a $80 \%$ em mais da metade dos antimicrobianos testados. De igual modo, no estudo realizado em um hospital público de Fortaleza, por Nogueira et al. (2009), ao longo de 2007, a taxa média anual de $\mathrm{IH}$ foi de $8,2 \%$, sendo o Staphylococcus aureus o responsável por $20 \%$ das cepas confirmadas laboratorialmente, apresentando elevadas taxas de resistência à meticilina $(77,3 \%)$.

RC: 66829

Disponível em: https://www.nucleodoconhecimento.com.br/saude/resistente-ameticilina 
O estudo de Ribeiro et al. (2019) realizado na UTI do Hospital Universitário da Universidade Federal do Vale do São Francisco, Petrolina, Pernambuco, entre janeiro e junho de 2018, evidenciou que a bactéria mais incidente em $14 \%$ dos aspirados de secreção traqueal foi Staphylococcus aureus, apresentando percentuais de resistência de $16,67 \%$ para meticilina. Nas amostras de hemoculturas, o S. aureus foi isolado em $12,8 \%$ dos casos, indicando $100 \%$ de resistência à meticilina. Semelhantemente, Oliveira et al. (2018), ao analisarem a prevalência de Staphylococcus aureus em pacientes internados no hospital público de Teresina, Piauí, no período de outubro a dezembro de 2015, obtiveram uma taxa de colonização de $S$. aureus de $31 \%$ em amostras da orofaringe e $12,8 \%$ em locais de inserção de cateter venoso central. Do total de pacientes estudados, a taxa de colonização por MRSA foi de $26,4 \%$, sendo que somente a orofaringe apresentou um perfil de resistência à meticilina de $73,52 \%$.

No estudo realizado por Rodrigues et al. (2015), em que se utilizaram o banco de dados do Hospital Universitário de Santa Maria, referente ao período de cinco anos (2007-2011), a taxa média de prevalência de MRSA nas diferentes culturas isoladas foi de $33,3 \%$, dos quais $15,13 \%$ foram provenientes da UTI. Corroborando com estes resultados, o estudo realizado por Cruvinel, Silveira e Soares (2011) com amostras do sítio nasal de pacientes hospitalizados na unidade de terapia intensiva do Hospital Regional de Ceilândia, Distrito Federal, no período de fevereiro a maio de 2010, apontou que 95\% dos pacientes apresentaram crescimento bacteriano positivo para Staphylococcus aureus, sendo 35\% meticilina resistente.

De acordo com Siqueira et al. (2018), em um estudo realizado em um hospital filantrópico do Espírito Santo entre julho de 2014 a junho de 2016, 511 pacientes hospitalizados em distintos setores, a exemplo da unidade de terapia intensiva, tiveram suas amostras biológicas (urina, sangue e secreções) analisadas quanto à presença de micro-organismos patogênicos. Como resultado, encontraram 96 amostras positivas com presença de $S$. aureus, das quais $27,8 \%$ das amostras sanguíneas e $41,4 \%$ das amostras de secreções indicaram a presença de MRSA. 
Outras medidas importantes a serem tomadas para minimizar esse problema de saúde pública são a identificação do agente causador da infecção, por meio das culturas bacterianas e testes laboratoriais, para que haja uma prescrição e administração apropriada do antibiótico. Esta determinação correta do prazo do tratamento poderá evitar o seu uso irracional e indiscriminado, o que reduzirá as possibilidades de desenvolvimento de resistência dos micro-organismos (MELO et al., 2019).

Com a finalidade de conhecer, identificar e realizar ações promocionais e preventivas quanto à disseminação de agentes infecciosos em instituições de saúde, os protocolos de cultura de vigilância ativa recomendados pela Anvisa têm por objetivo a detecção de casos novos, adicionais e óbitos por MRSA. Esse programa consiste em culturas de triagem ativa precoce dos pacientes, principalmente em unidades de terapia intensiva, a partir do momento da internação hospitalar, seguido de exames periódicos e vigilância contínua daqueles pacientes que adquirem MRSA durante o período de permanência no hospital (CRUZ; SILVA; MAGALHÃES, 2018).

Garcia, Silva e Oliveira (2019), analisando 461 laudos de culturas de vigilância epidemiológica de pacientes internados nas UTIs de um Hospital de Ensino em Minas Gerais, entre janeiro a julho de 2014, observaram que a prevalência de pacientes colonizados positivamente para MRSA foi de 9,7\%, sendo que, destas, $88,9 \%$ foram isoladas na UTI adulto e $11,1 \%$ da UTI neonatal e pediátrica. Esses resultados divergem do estudo realizado em um hospital da zona sul do Rio de Janeiro, no período de março de 2012 a março de 2013, por Gonçalves et al. (2013), no qual, por meio da análise das culturas de vigilância ativa dos pacientes internados na UTI, constataram que das 2.517 amostras analisadas, 132 foram positivas para Staphylococcus aureus, das quais apenas 44 indicaram a presença de MRSA. Neste estudo foi demonstrado a eficácia no uso das culturas de vigilância ativa no controle de infecções por MRSA.

Cruz, Silva e Magalhães (2018) analisaram entre os meses de março e dezembro de 2018, 591 culturas de vigilância ativa de pacientes internados no Hospital 
Universitário da Universidade Federal de Juiz de Fora, em Minas Gerais. Nesse estudo, entre os pacientes transferidos de outra instituição que permaneceram mais de 96 horas internados, 81 tiveram cultura positiva, dos quais 46,9\% apresentaram Staphylococcus aureus resistente à meticilina como linhagem prevalente em suas culturas de vigilância. Os demais pacientes que possuíam como motivo da internação terem sido submetidos a algum procedimento invasivo e internados por no mínimo 48 horas, realizado terapia renal substitutiva ou que foram internados por no mínimo 30 dias dentro dos últimos 90 dias, a infecção por MRSA foi de 61,5\%. Obtendo número pouco divergente do estudo de Cruz, Silva e Magalhães (2018), Moraes et al (2013), em sua pesquisa de vigilância ativa realizada entre o período de agosto de 2007 e janeiro de 2008, com 85 pacientes em um hospital público terciário de São Paulo, verificaram que, entre os grupos que apresentaram variáveis igualmente preditoras (pacientes transferidos de outra unidade de saúde como também aqueles internados na UTI), o MRSA foi responsável por 54,5\% dos casos de infecção. Desse total, tanto os pacientes colonizados e/ou infectados, realizaram algum tipo de procedimento invasivo, como uso de sonda vesical de demora e cateter venoso central.

De acordo com as novas orientações do Centro de Controle de Doenças (CDC), a fim de conter as infecções hospitalares, faz-se necessário adotar medidas de prevenção antes e pós-exposição aos riscos, chamadas de Precauções Padrão (PP) e Precauções Baseadas em Rotas de Transmissão (PBT) (MARTINS et al., 2014). Uma das precauções mais importantes são as Precauções por Contato. Diante do quadro da colonização ou infecção por algum micro-organismo, a exemplo do $S$. aureus meticilina resistente, é preferível que os pacientes sejam colocados em um quarto individual. Quando não for possível, os mesmos devem ser colocados em sistemas de coorte - agrupando portadores de bactérias com o mesmo perfil de resistência antimicrobiana no mesmo quarto - mantendo uma distância de pelo menos 2 metros entre os leitos. Todos os equipamentos utilizados na assistência ao paciente, como termômetro e estetoscópio devem ser desinfetados ou esterilizados 
e, preferencialmente, de uso exclusivo, evitando-se o compartilhamento (LIMA et al., 2015).

\section{CONSIDERAÇÕES FINAIS}

Diante dos cenários expostos nesse estudo, é possível constatar as elevadas taxas de casos de infecções nosocomiais desencadeadas por Staphylococcus aureus resistente à meticilina em pacientes internados em UTIs do Brasil. Com isso, podese concluir que o micro-organismo Staphylococcus aureus é um patógeno de grande relevância médica, principalmente a cepa resistente à meticilina, quando se trata de infecções relacionadas à saúde nos setores de unidades de terapia intensiva, acometendo os pacientes internados nessa área hospitalar, podendo levá-los ao óbito.

A descoberta dos antibióticos trouxe um grande avanço para o setor da saúde no que se refere ao tratamento de infecções microbianas. $O$ uso errôneo e indiscriminado, tanto pelos profissionais de saúde, quanto pela população, tem desencadeado um impacto negativo em sua eficácia e aumentado não só a pressão do processo natural de desenvolvimento da resistência antimicrobiana pelos microorganismos, como a elevação dos custos e da morbimortalidade, ao passo que cepas multirresistentes são geradas e medicamentos diminuem a sua eficácia, tornando-se uma ameaça crescente para o setor de saúde pública não somente a nível nacional, como também a nível mundial.

A insuficiência crescente de opções terapêuticas enfatiza a urgência da adesão às práticas preventivas no âmbito hospitalar com o propósito da promoção à assistência integrada e controle desse agravo, como também de investir em pesquisas e desenvolvimento de novos medicamentos que garantam a eficácia do tratamento das infecções causadas por micro-organismos resistentes, como o MRSA, e a segurança do paciente. Diante desse cenário, é imprescindível a adoção ao uso das medidas de precauções a fim de minimizar os riscos de transmissão de microorganismos patogênicos nos hospitais. Estratégias administrativas, ações educativas

RC: 66829

Disponível em: https://www.nucleodoconhecimento.com.br/saude/resistente-ameticilina 
de higienização, tanto das mãos dos profissionais de saúde e colaboradores, como do ambiente da unidade de saúde, principalmente de áreas críticas como a UTI, uso racional e responsável de antibióticos e programas de vigilância epidemiológica, incluem fundamentalmente as ferramentas mais importantes para a redução da ocorrência de infecções relacionadas à saúde.

\section{REFERÊNCIAS}

ALFOUZAN, Wadha; DHAR, Rita; UDO, Edet. Genetic lineages of methicillinresistant Staphylococcus aureus acquired during admission to na intensive care unit of a general hospital. Med Princ Pract, [Switzerland], v. 26, p. 113-117, 2017. Disponível em: <https://pubmed.ncbi.nlm.nih.gov/27829243/>. Acesso em: 29 ago. 2020.

AMADOR, Jenifer Fernanda Sanches; BASSO, Lahis Cristina; VIEIRA, Suellen Laís Vicentino. Prevalência de Staphylococcus aureus em superfícies de unidade de terapia intensiva. Arquivos do Mudi, [S. I.], v. 22, n. 2, p. 1-10, out. 2018. Disponível em: <http://periodicos.uem.br/ojs/index.php/ArqMudi/article/view/42861>. Acesso em: 23 ago. 2020.

BASTOS, Ive Dias Mangueira et al. Perfil bacteriano de amostras microbiológicas de pacientes internados na Clínica Cirúrgica de um Hospital Universitário de Pernambuco. Vittalle, [Rio Grande], v. 32, n. 1, p. 108-121, 2020.

BRASIL. Ministério da Saúde, Agência Nacional de Vigilância Sanitária. Resolução no 7, de 24 de fevereiro de 2010. Dispõe sobre os requisitos mínimos para funcionamento de Unidades de Terapia Intensiva e dá outras providências. Brasília, DF: Anvisa, $2010 . \quad$ Disponível em: $<$ https://www.saude.mg.gov.br/images/documentos/RDC-7_ANVISA\%20240210>. Acesso em: 28 fev. 2020.

BRASIL. Ministério da Saúde. Portaria n 64, de 11 de dezembro de 2018. Diário Oficial da União, Brasília, DF, p. 59, 14 dez. 2018. Brasília, 2018. Disponível em:

RC: 66829

Disponível em: https://www.nucleodoconhecimento.com.br/saude/resistente-a$\underline{\text { meticilina }}$ 
<http://www.in.gov.br/materia/-

/asset_publisher/Kujrw0TZC2Mb/content/id/55217765/do1-2018-12-14-portaria-n-64de-11-de-dezembro-de-2018-55217696>. Acesso em: 04 mar. 2020.

BRASIL. Ministério da Saúde. Agência Nacional de Vigilância Sanitária. Manual de Microbiologia clínica para o controle de infecção relacionada à assistência à saúde. Módulo 6: Detecção e Identificação de Bactérias de Importância Médica. Brasília, DF: $\quad$ Anvisa, 2013.

Disponível em: <https://www20.anvisa.gov.br/segurancadopaciente/index.php/publicacoes/item/dete ccao-e-identificacao-de-bacterias-de-importancia-medica $>$. Acesso em: 20 fev. 2020.

BULLÉ, Danielly Joani et al. Prevalência de Staphylococcus aureus meticilina resistentes em profissionais de saúde. Rev Enferm UFSM, [Santa Maria], v. 6, n. 2, p. 198-205, abr.jun. 2016.2 Disponível em: <https://periodicos.ufsm.br/reufsm/article/view/16753>. Acesso em: 23 fev. 2020.

CAMILO, Carla Juliana; PEDER, Leidy Daiane de; SILVA, Claudinei Mesquita da. Prevalência de Staphylococcus aureus meticilina resistente em profissionais de enfermagem. Rev Saúde e Pesq, Maringá, PR, v. 9, n. 2, p. 361-371, maio/ago. 2016.

em: <https://periodicos.unicesumar.edu.br/index.php/saudpesq/article/view/4788/2849>. Acesso em: 23 fev. 2020.

CASTRO-OROZCO, Raimundo et al. Antimicrobial resistance trends in methicillinresistant and methicillin-susceptible Staphylococcus aureus and Staphylococcus epidermidis isolates obtained from patients admitted to intensive care units. 20102015. Rev Fac Med (online), [Bogotá], v. 67, n. 3, p. 221-228, 2019. Disponível em: $<$ http://www.scielo.org.co/scielo.php?pid=S012000112019000300409\&script=sci_abstract\&tlng=en>. Acesso em: 29 ago. 2020.

CATÃO, Raïssa Mayer Ramalho et al. Prevalência de infecções hospitalares por Staphylococcus aureus e perfil de suscetibilidade aos antimicrobianos. Rev Enferm RC: 66829

Disponível em: https://www.nucleodoconhecimento.com.br/saude/resistente-ameticilina 
UFPE on line., Recife, v. 7, n. 8, p. 5257-5264, ago. 2013. Disponível em: $<$ https://periodicos.ufpe.br/revistas/revistaenfermagem/article/view/11801/14181>. Acesso em: 17 fev. 2020.

CRUVINEL, A. R.; SILVEIRA, A. R.; SOARES, J. S. Perfil antimicrobiano de Staphylococcus aureus isolado de pacientes hospitalizados em UTI no Distrito Federal. Cenarium Pharmacêutico, [S. I.], ano 4, n. 4, maio/nov. 2011. Disponível em:

<http://www.unieuro.edu.br/sitenovo/revistas/downloads/farmacia/cenarium_04_16.p df>. Acesso em: 01 ago. 2020.

CRUZ, Franciele Ferreira da et al. Segurança do paciente na uti: uma revisão da literatura. Revista Científica FacMais, [S. I.], v. 12, n. 1, p. 167-187, abr. 2018. Disponível em: <https://revistacientifica.facmais.com.br/wpcontent/uploads/2018/06/12.-SEGURAN\%C3\%87A-DO-PACIENTE-NA-UTI-UMAREVIS\%C3\%83O-DA-LITERATURA.pdf>. Acesso em: 07 set. 2020.

CRUZ, Renata Fiuza; SILVA, Gabriela Matheus Messias; MAGALHÃES, Maria da Consolação. Perfil microbiológico dos pacientes submetidos à cultura de vigilância ativa em um hospital universitário da Região Sudeste de Minas Gerais. HU Rev, Juiz de Fora, v. 44, n. 3, p. 361-367, jul./set. 2018. Disponível em: <https://periodicos.ufjf.br/index.php/hurevista/article/view/16951/18760>. Acesso em: 18 fev. 2020.

DUARTE, Felipe Crepaldi et al. Bacteremia causada por Staphylococcus aureus: uma análise de quinze anos da sensibilidade a antimicrobianos em um hospital terciário do Brasil. Rev Epidemiol Controle Infecç, Santa Cruz do Sul, v. 8, n. 3, p. 232-238, jul. 2018.

Disponível

em: $<$ https://online.unisc.br/seer/index.php/epidemiologia/article/view/11245>. Acesso em: 17 fev. 2020.

FERREIRA, Larissa de Lima et al. Cuidado de enfermagem nas Infecções Relacionadas à Assistência à Saúde: Scoping review. Rev Bras Enferm (online), RC: 66829

Disponível em: https://www.nucleodoconhecimento.com.br/saude/resistente-ameticilina 
[Brasília] v. 72, n. 2, p. 498-505, 2019. Disponível em: <https://www.scielo.br/pdf/reben/v72n2/pt_0034-7167-reben-72-02-0476>. Acesso em: 10 set. 2020.

FRANÇA, Camila Letícia da Costa; FREITAS, Rafael Limeira de. Unidade de terapia intensiva e os fatores de infecção. Rev Cient Enfem, São Paulo, v. 9, n. 26, p. 32 39 , 2019.

Disponível

em:

$<$ https://www.recien.com.br/index.php/Recien/article/view/288>. Acesso em: 23 set. 2020.

FREITAS, ANA et al. Abordagem terapêutica nas infecções por Staphylococcus aureus resistentes à meticilina. Gaz Med, [Portugal], v. 3, n. 4, p. 186-190, out./dez. 2016. Disponível

em: $<$ https://www.gazetamedica.pt/index.php/gazeta/article/view/47>. Acesso em: 23 set. 2020.

GARCIA, Patricia Guedes; SILVA, Isabela Aparecida Ribeiro da; OLIVEIRA, Leonardo Romaniello Gama de. Colonização por Staphylococcus aureus resistente à meticilina em pacientes de unidades de terapia intensiva. Rev Méd Minas Gerais, [Belo Horizonte], v. 29, p. 1-5, e-2016, 2019. Disponível em: <http://www.rmmg.org/artigo/detalhes/2511>. Acesso em: 20 ago. 2020.

GONÇALVES, Ana Cristina Nunes et al. Incidência de infecções provocadas por Staphylococcus aureus resistente a meticilina em um hospital da zona sul do Rio de Janeiro. Saúde \& Amb Rev, Duque de Caxias, RJ, v. 8, n. 1, p. 54-57, jan./jun. 2013. Disponível em: <https://www.semanticscholar.org/paper/INCID\%C3\%8ANCIADE-INFEC\%C3\%87\%C3\%95ES-PROVOCADAS-POR-aureus-A-EM-CardozoGon\%C3\%A7alves/d49e031186a3b46fc151a361b67156a255e9c5ea?p2df>. Acesso em: 17 ago. 2020.

GURUNG, Raja Ram; MAHARJAN, Prashanna; GHARTI CHHETRI, Ganga. Antibiotic resistance pattern of Staphylococcus aureus with reference to MRSA isolates from pediatric patients. Future Sci OA, [S. I.], v.6, n. 4, Feb. 2020. RC: 66829

Disponível em: https://www.nucleodoconhecimento.com.br/saude/resistente-ameticilina 
Disponível em: <https://www.future-science.com/doi/10.2144/fsoa-2019-0122>. Acesso em: 21 set. 2020 .

HOLANDA, Cecília Maria de Carvalho Xavier; ARIMATEIA, Dayse Santos; MOTTA NETO, Renato. Manual de Bacteriologia e de Enteroparasitos. Natal: Ed. UFRN, 2017, 134 p. ISBN 978-85-425-0743-0. Disponível em: <http://repositorio.ufrn.br/handle/123456789/24343>. Acesso em: 8 set. 2020.

IFA, Alemu Chemeda. The emergence of methicillin-resistant Staphylococcus aureus: the problem to control it. Int J Rec Res Life Sci, [S. I.], v. 6, n. 4, p. 1-9, Oct./Dec. 2019.

Disponível em: <https://www.researchgate.net/publication/338230288>. Acesso em: 23 ago. 2020.

LABNETWORK. BRCast auxilia laboratórios de microbiologia a implementar as normas do EuCast. Labnetwork: conectando o universo das análises clínicas e instrumentação analítica. [S.I.], 24 nov. 2016. Disponível em: $<$ https://www.labnetwork.com.br/especiais/como-o-brcast-auxilia-laboratorios-demicrobiologia-a-implementar-as-normas-do-eucast/>. Acesso em: 04 mar. 2020.

LIMA, Maíra Ferreira Pinto et al. Staphylococcus aureus e as infecções hospitalares - revisão de literatura. Revista Uningá Review, [S. I.], v. 21, n. 1, p. 32-39, jan./mar. 2015

Disponível

em:

<http://revista.uninga.br/index.php/uningareviews/article/view/1616>. Acesso em: 22 ago. 2020.

LOPES, Letícia Pimenta et al. Prevalência de Staphylococcus aureus resistente à oxacilina isolado em profissionais de enfermagem. Rev Rene (Online), [S. I.], v. 19, e32478, 2018. Disponível em: <http://periodicos.ufc.br/rene/article/view/32478>. Acesso em: 28 jun. 2020.

LOUREIRO, Rui João et al. O uso de antibióticos e as resistências bacterianas: breves notas sobre a sua evolução. Rev Port Saúde Pública, Lisboa, v. 34, n. 1, p. 77-84, 2016.

RC: 66829

Disponível em: https://www.nucleodoconhecimento.com.br/saude/resistente-ameticilina 
MARTINS, Andreza F. et al. Controle e monitoramento de microrganismos multirresistentes. Porto Alegre, RS, 2014. Disponível em: <http://lproweb.procempa.com.br/pmpa/prefpoa/cgvs/usu_doc/controle_e_monitoram ento_de_microrganismos_multirresistentes.pdf>. Acesso em: 21 fev. 2020.

MELO, Felipe da Silva de et al. Uso racional de antimicrobianos na unidade de terapia intensiva. Rev Enferm UFPE on line, Recife, v. 13, n. 5, p. 1475-1484, maio. 2019.

em: $<$ https://periodicos.ufpe.br/revistas/revistaenfermagem/article/view/238666>. Acesso em: 01 set. 2020.

MENEZES, Joana Marília Rodrigues; PORTO, Maria Luísa Souto; PIMENTA, Carla Lauise R. M. Perfil da infecção bacteriana em ambiente hospitalar. Rev Ciênc Méd Biol, Salvador, v. 15, n. 2, p. 199-207, maio/ago. 2016.

MICHELIN, Ana Flávia; FONSECA, Márcia Regina Campos Costa da. Perfil epidemiológico das infecções hospitalares na unidade de terapia intensiva de um hospital terciário. Nursing (São Paulo), São Paulo, v. 21, n. 236, p. 2037-2041, 2018.

MORAES, Graciana Maria de et al. Infecção ou colonização por micro-organismos resistentes: identificação de preditores. Acta Paul Enferm, v. 2, n. 26, p. 185-191, 2013. Disponível em: <https://www.scielo.br/pdf/ape/v26n2/v26n2a13>. Acesso em: 15 out. 2020.

MOREIRA, Ana Cândida Martins Grossi; SANTOS, Rosiane Ribeiro dos; BEDENDO, João. Prevalência e perfil de sensibilidade de Staphylococcus aureus isolados em pacientes e equipe de enfermagem. Cienc Cuid Saúde, [S. I.], v. 12, n. 3, p. 572579, jul./set. $2013 . \quad$ Disponível em: $<$ http://periodicos.uem.br/ojs/index.php/CiencCuidSaude/article/view/17609>. Acesso em: 30 ago. 2020.

RC: 66829

Disponível em: https://www.nucleodoconhecimento.com.br/saude/resistente-ameticilina 
NASCIMENTO, Thiago C. et al. Methicillin-resistant Staphylococcus aureus isolated from na intensive care unit in Minas Gerais, Brazil, over a six-year period. Braz J Infect Dis, [Salvador], v. 22, n. 1, p. 55-59, Jan./Feb. 2018. Disponível em: $<$ https://www.sciencedirect.com/science/article/pii/S1413867017307742>. Acesso em: 29 ago. 2020.

NOGUEIRA, Paula Sacha Frota et al. Perfil da infecção hospitalar em um hospital universitário. Rev Enferm UFRJ, Rio de Janeiro, RJ, v. 17, n. 1, p. 96-101, jan./mar. 2009. Disponível em: <http://files.bvs.br/upload/S/0104-3552/2009/v17n1/a017.pdf>. Acesso em: 02 set. 2020.

OLIVEIRA, Daniele Martins de Sousa et al. High rates of methicillin-resistant Staphylococcus aureus colonisation in a Brazilian Intensive Care Unit. Intensive Crit Care Nurs, [Edinburgh], v. 49, p. 51-57, Dec. 2018. Disponível em: <https://www.sciencedirect.com/science/article/abs/pii/S0964339718300612?via\%3D ihub>. Acesso em: 29 ago. 2020.

PEREIRA, Bruna Letícia et al. Colonização por microrganismos em colaboradores da saúde. Enferm Bras, [S. I.], v. 18, n. 2, p. 213-219, 2019.

PEREIRA, Francisco Gilberto Fernandes et al. Caracterização das infecções relacionadas à assistência à saúde em uma unidade de terapia intensiva. Rev Visa em Debate, Fortaleza, v. 4, n. 1, p. 70-77, 2016.

PHARMACEUTICAL Research and Manufacturers of America. Medicines in Development: Skin Diseases. Washington, 2018, 52 p. Disponível em: $<$ https://www.phrma.org/Report/List-of-2018-Medicines-in-Development-for-SkinDisease>. Acesso em: 4 mar. 2020.

RENNER, Jane Dagmar Pollo; CARVALHO, Édina Daiane. Microrganismos isolados de superfícies da UTI adulta em um hospital do Vale do Rio Pardo - RS. Rev Epidemiol Controle Infecç, [Santa Cruz do Sul], v. 3, n. 2, p. 40-44, abr./jun. 2013. Disponível em:

RC: 66829

Disponível em: https://www.nucleodoconhecimento.com.br/saude/resistente-ameticilina 
$<$ https://online.unisc.br/seer/index.php/epidemiologia/article/view/3290>. Acesso em: 12 set. 2020.

RIBEIRO, Tércio de Sá et al. Ocorrência e perfil bacteriano de culturas coletadas em pacientes internados na unidade de terapia intensiva em um hospital terciário. HU Revista, Juiz de Fora, v. 45, n. 2, p. 122-133, 2019. Disponível em: <http://docs.bvsalud.org/biblioref/2020/01/1048773/25933-outros-111436-3-1020191107>. Acesso em: 29 ago. 2020.

RODRIGUES, Mônica de Abreu et al. Prevalence of methicillin-resistant Staphylococcus aureus in a University Hospital in the South of Brazil. Braz J Pharm Sci, [São Paulo], v. 51, n. 1, p. 35-41, Jan./Mar. 2015. Disponível em: $<$ https://www.scielo.br/scielo.php?script=sci_arttext\&pid=S1984$82502015000100035 \&$ lng=en\&tlng=en>. Acesso em: 30 ago. 2020.

SILVA, Ana Elisa Pereira. Incidência de Staphylococcus multirresistentes a antimicrobianos nas mãos dos profissionais de unidade básica de saúde. 2017. 101 f. Dissertação (Mestrado em Ciências Ambientais) - Universidade Brasil, Fernandópolis, São Paulo, 17 mar. 2017. Disponível em: <https://universidadebrasil.edu.br/portal/_biblioteca/uploads/20200313201229.pdf>. Acesso em: 29 ago. 2020.

SILVA, Moisés Oliveira da; AQUINO, Simone. Resistência aos antimicrobianos: uma revisão dos desafios na busca por novas alternativas de tratamento. Rev Epidemiol Controle Infecç, Santa Cruz do Sul, v. 8, n. 4, p. 472-482 out./dez. 2018. Disponível em: $\quad$ <https://online.unisc.br/seer/index.php/epidemiologia/article/view/11580>. Acesso em: 28 jun. 2020.

SIQUEIRA, Carla. C. M. et al. Prevalence and antimicrobial susceptibility profile of microorganisms in a university hospital from Vitória, ES, Brazil. J Bras Patol Med Lab, [Rio de Janeiro], v. 54, n. 2, p. 76-82, Apr. 2018.

RC: 66829

Disponível em: https://www.nucleodoconhecimento.com.br/saude/resistente-ameticilina 
SOARES, Sara Gabrielly de Sousa Costa et al. Characterization of the infections related to health care in a teaching hospital in the Northeastern of Brazil. Rev Enferm UFPI, [Teresina], v. 6, n. 2, p. 37-43, abr./jun. 2017.

SOUSA, Daniele Martins de et al. Infecção por Staphylococcus aureus resistente em unidades de terapia intensiva: revisão integrativa. Rev Enferm UFPE on line, Recife, v. 10, n. 4, p. 1315-1323, abr. 2016. Disponível em: $<$ https://periodicos.ufpe.br/revistas/revistaenfermagem/article/view/11119>. Acesso em: 10 set. 2020.

TEIXEIRA, Arthur Alves et al. Avaliação da contaminação por Staphylococcus aureus resistente a droga beta-lactâmica de estetoscópios dos profissionais de um Hospital Escola em uma cidade do interior do Rio de Janeiro. Saber Digital, [S. I.], v. 9, n. 2, p. 117-128, out. 2016. Disponível em: $<$ http://revistas.faa.edu.br/index.php/SaberDigital/article/view/214>. Acesso em: 17 set. 2020.

TONG, Steven Y. C. et al. Staphylococcus aureus Infections: Epidemiology, Pathophysiology, Clinical Manifestations, and Management. Clin Microbiol Rev, [Washington], v. 28, n. 3, July. 2015.

WATKINS, Richard R.; HOLUBAR, Marisa; DAVID, Michael Z. Antimicrobial resistance in methicillin-resistant Staphylococcus aureus to newer antimicrobial agentes. Antimicrob. Agentes Chemother, [Washington], v. 63, n.12, e01216-19, Dec. 2019. Disponível em: <https://aac.asm.org/content/63/12/e01216-19>. Acesso em: 27 ago. 2020.

ZURITA, Jeannete; MEJÍA, Carlos; GUZMÁN-BLANCO, Manuel. Diagnosis and susceptibility testing of methicillin-resistant Staphylococcus aureus in Latin America. Braz J Infect Dis, [Salvador], v. 14, supl. 2, s.97-106, 2010.

Enviado: Novembro, 2020.

RC: 66829

Disponível em: https://www.nucleodoconhecimento.com.br/saude/resistente-ameticilina 
Aprovado: Novembro, 2020.

RC: 66829

Disponível em: https://www.nucleodoconhecimento.com.br/saude/resistente-ameticilina 